\title{
Extensão universitária e formação docente: tecendo diálogo sobre concepções, sentidos e construções
}

\section{University extension and teacher training: weaving a dialogue about conceptions, meanings and constructions}

\author{
Andréa Kochhann ${ }^{1 *}$
}

\begin{abstract}
RESUMO
O presente texto é reflexo de uma pesquisa de doutoramento em educação pela Universidade de Brasília, que teve como objeto de investigação a formação docente, delimitada em analisar como a formação docente ocorre, pelas atividades de projetos de extensão, realizadas durante o ano de 2018, vinculados ao curso de Pedagogia da Universidade Estadual de Goiás. Neste trabalho apresentamos o posicionamento dos docentes que coordenaram os oito projetos de extensão universitária, estudados na pesquisa, no tocante a concepção e o sentido da extensão universitária, bem como as dificuldades e possibilidades de construção da mesma no processo formativo. A metodologia de análise das entrevistas seguiu os Núcleos de Significação, de Aguiar e Ozella (2012) e com embasamento teórico em Reis (1996), Gurgel (1986), Sousa (2000), Síveres (2013), Saviani (2009), FORPROEX (2012) e outros. A concepção se apresenta acadêmica, o sentido de transformação social e a construção com dificuldades institucionais e pedagógicas, mas com possibilidades de efetivação pela contribuição acadêmica e social.
\end{abstract}

Palavras-chave: Extensão Universitária; Formação Docente; Resolução CNE/CES n. 07/2018; Núcleos de Significação.

\section{ABSTRACT}

Resumo no segundo idioma, com as mesmas regras e a mesma formatação do anterior. This text is a reflection of a doctoral research in education by the University of Brasília, which had as its object of investigation the teacher education, delimited on analyzing how teacher education occurs, through the activities of extension projects, carried out during the year 2018, linked to the Pedagogy course at the State University of Goiás. In this paper we present the position of the professors who coordinated the eight university extension projects, studied in the research, regarding the conception and meaning of university extension, as well as the difficulties and possibilities of construction of the same in the formative process. The methodology for analyzing the interviews followed the Meaning Nucleus, by Aguiar and Ozella (2012) and with theoretical basis in Reis (1996), Gurgel (1986), Sousa (2000), Síveres (2013), Saviani (2009), FORPROEX (2012) and others. The conception is academic, the sense of social transformation and construction with institutional and pedagogical difficulties, but with possibilities of realization through academic and social contribution.

Keywords: University Extension; Teacher Training; CNE/CES Resolution n. 07/2018; Meaning Nuclei.

\footnotetext{
${ }^{1}$ Universidade Estadual de Goiás (UEG).

*E-mail: andreakochhann@yahoo.com.br
} 


\section{INTRODUÇÃO}

Discutir formação docente é algo denso, tenso e intenso. Discutir a formação docente pela extensão universitária é ainda mais denso, tenso e intenso, principalmente considerando que a extensão universitária foi regulamentada no processo formativo, somente em dezembro de 2018 pela Resolução CNE/CES n. 07, que obriga todas as instituições de ensino superior curricularizar no mínimo $10 \%$ da carga horária total dos cursos serem realizadas em atividades de extensão universitária.

A discussão sobre extensão universitária no processo formativo tem sido pouco pesquisada e com raras publicações, mediante resultado do Estado da Arte, realizado durante a pesquisa de doutoramento. Isso pode implicar no fato de que a temática está sendo pouco debatida entre os pares e justifica o presente texto enquanto provocação ao mesmo.

Destarte, o problema que norteia a escrita desse texto é "Como a extensão universitária se apresenta no processo formativo considerando sua concepção, seu sentido e sua construção?”. Para responder a esse problema, entrevistamos 9 docentes que coordenam 8 projetos de extensão vinculado ao curso de Pedagogia, da Universidade Estadual de Goiás, executados durante o ano de 2018, sendo que os projetos são considerados como consolidados, por acontecerem há mais de 3 anos consecutivos.

O referencial teórico que possibilita as análises das entrevistas se sustenta em Reis (1996) que trata da extensão na concepção acadêmica processual e orgânica, Gurgel (1986) que aborda a extensão enquanto laboratório ou estágio vivo, Sousa (2000) com a formação para alienação ou emancipação, Síveres (2013) que defende a extensão enquanto processo de aprendizagem e não meramente prestação de serviço ou assistencialismo, Saviani (2009) no tocante a formação docente no Brasil, FORPROEX (2012) que apresenta as diretrizes, objetivos e concepções de extensão universitária no Brasil e outros.

O trabalho se alicerça na base analítica os Núcleos de Significação de Aguiar e Ozella (2012) que consideram o processo histórico, a totalidade, a contradição e a dialética expressas na linguagem do sujeito, que é carregada de sentidos e significados. Os núcleos de significação são compostos por três estapas: 1- organização dos préindicadores, 2- articulação dos pré-indicadores e, 3 - construção dos núcleos de significação. 
Para Aguiar e Ozella (2013, p. 308 - 309), os pré-indicadores referem-se a "palavras inseridas no contexto que lhe atribui significado, entendendo aqui como contexto desde a narrativa do sujeito até as condições histórico-sociais que o constituem [...] trechos de fala compostos por palavras articuladas que compõem um significado". O pesquisador/entrevistador vai selecionando as palavras com significado, pois para os autores $(2013$, p. 308) "Buscamos, a partir do que foi dito pelo sujeito, entender aquilo que não foi dito: apreender a fala interior do professor, o seu pensamento, o processo (e as contradições presentes nesse processo) de constituiçãa dos sentidos que ele atribui à atividade de docência.".

Os pré-indicadores podem ser palavras expressas ou objetivadas, ou seja, aquilo que não foi dito ou aquilo que foi dito como algo encomendado ou decorado, pode não representar à essência, sendo importante perceber/sentir a emoção, a história, o contexto, a subjetividade do entrevistado. Essa tessitura constitui o processo de objetivação, permeando a saída da aparência à essência, em um processo dialético e contraditório, por um esforço de compreensão do pesquisador das questões subjetivas do entrevistado, configurando a análise de significações.

As palavras selecionadas, na segunda etapa, são agrupadas pela sua similaridade, complementaridade ou contraposição no intuito de perceber como se articulam constituindo a realidade abstrata, como se organizassem a tese e a antítese a partir dos pré-indicadores. Assim, caminhamos para a terceira fase, que é a construção dos núcleos de significação ou a síntese, que para Aguiar e Ozella (2013, p. 310) devem "ser entendidos como um momento superior de abstração, o qual, por meio da articulação dialética das partes - movimento subordinado à teoria -, avança em direção ao concreto pensado, às zonas de sentido.”.

\section{EXTENSÃO UNIVERSITÁRIA E FORMAÇÃO DOCENTE: o que dizem os teóricos}

A discussão sobre a relação entre extensão universitária e a formação docente, ainda é rasa e rara, conforme Estado do Arte realizado no doutorado em educação (KOCHHANN, 2019) e alguns elementos surgem como explicativos para tal fato, dentre eles a falta de concepção nas ações extensionistas, visto que os trabalhos que existem focam a socialização da ação prática, sem mencionar e/ou discutir na teoria de concepção 
que alicerça a prática. Isso pode ser consequência do processo histórico de constituição da extensão universitária no Brasil.

Apesar de poucos trabalhos, podemos apresentar que Reis (1996) trata da extensão na concepção acadêmica processual e orgânica, Gurgel (1986) aborda a extensão enquanto laboratório ou estágio vivo, Síveres (2013) defende a extensão enquanto processo de aprendizagem e não meramente prestação de serviço ou assistencialismo, FORPROEX (2012) apresenta as diretrizes, objetivos, desafios e concepções de extensão universitária no Brasil e outros e, Saviani (2009) no tocante a formação docente no Brasil.

A concepção de extensão universitária no Brasil foi muito influenciada por concepção estrangeira. A extensão europeia tinha características assistenciais e a norteamericana de prestação de serviços vinculados ao setor empresarial, mas a latina foi concebida pelos movimentos sociais para a transformação, principalmente por influência da Carta de Córdoba. Apesar da influência de Córdoba, a historicidade da extensão universitária brasileira é muito marcada com a prestação de serviços e assistencialismo, sendo necessário um novo modo de compreender as atividades extensionistas - de forma processual e contínua.

Reis (1996) apresenta duas linhas de concepção de extensão universitária: eventista-inorgânica e processual-orgânica. O autor defende a construção da pesquisa, do ensino e da extensão de forma indissociável na convivência com o diferente, na diferença e com amor e por isso apresenta a necessidade de compreender que as ações extensionistas podem ser eventistas-inorgânicas e processual-orgânica. Os estudos de Reis (1996, p. 41) fomentam a compreensão de que as ações eventista-inorgânica se caracterizam por "prestação de serviços ou na realização de eventos, isolados ou desvinculados do contexto ou do processo ensino-aprendizagem e de produção do conhecimento da universidade.”, o que não seria interessante para uma formação emancipadora dos sujeitos, por ser imediatista e temporal, de caráter assistencialista ou de intervenção.

Na percepção de Reis (1996) e corroboramos com o autor, as ações de caráter processual-orgânica se configuram na contra-mão da eventista-inorgânica, visto serem permanentes ou contínuas, primando pela indissociabilidade com ensino e pesquisa, no intuito de transformação tanto da sociedade quanto do acadêmico pelo movimento de formação para a emancipação. O autor deixa claro que a ruptura é grande e que precisa enfrentar algumas contradições e realinhamento de ordem política, visto o percurso 
histórico das universidades brasileiras e as atividades extensionistas existentes, em atendimento ao capital.

Já Gurgel (1986) discute que a extensão deve ser compreendida como um laboratório vivo, se aproximando do que significa um estágio supervisionado, mas não o sendo. Para o autor, a extensão universitária favorece uma formação acadêmica com base na realidade concreta e na aprendizagem, pois apresenta um campo de estágio vivo e renovado, ou seja, um verdadeiro laboratório de aprendizagens, porém não com tubos de ensaio mas vivo. Um currículo que fomenta uma prática extensionista como princípio de aprendizagem ou laboratório vivo, pode trazer uma formação docente crítica, omnilateral e emancipadora.

O autor defende uma formação do acadêmico que favoreça a transformação da sociedade, as atividades de extensão promovem uma vivência real que favorece o amadurecimento acadêmico que favorece a formação profissional, preparando-os para o mundo real para a comunicação e não para domesticação. Para isso, é preciso planejar ações extensionistas que primem pela comunicação, formação crítica e emancipadora. Essa formação pode vir a ser, se a extensão for concebida como princípio de aprendizagem, que se alicerça na pedagogia histórico-crítica e no currículo históricocrítico, pois prima pelo conhecimento criativo e inovador, pela reflexão e interdisciplinaridade e pela formação de sujeitos concretos. Sujeitos ativos em todo processo extensionista.

O processo na extensão, situado nas fronteiras institucionais e sociais, abre horizontes para um conhecimento mais criativo e inovador, fortalecendo um percurso mais compreensivo que informativo, mais reflexivo que transferidor de conhecimentos, mais produtivo que armazenador, mais invenção que enquadramento, mais possibilidades que certezas, mais sentido que direção, mais interdisciplinaridade que disciplinaridade, mais complexidade que simplificação, mais sujeitos que expectadores, mais vivências que exigências. (SÍVERES, 2013, p. 30)

A extensão universitária como princípio de aprendizagem pode fomentar a emancipação, mas nas sociedades capitalistas, toda forma de trabalho, em suas relações sociais estabelecidas podem vir a ser para a alienação e reprodução ou para a emancipação e autonomia, podendo ser nas instituições de ensino superior pelo ensino, pesquisa e extensão.

A Extensão Universitária, como instrumento de alienação, tem servido para manter o status quo e a hegemonia de uma classe. Apresenta-se, neste caso, 
não como uma 'prática social', mas como um fetichismo dentro da Universidade. Toma-se a Extensão como um 'fato independente da dinâmica do real' e a naturaliza. Contraditoriamente, a Extensão pode também assumir papel de instrumento de emancipação, de desenvolvimento das capacidades humanas. Isso acontece quando sua prática é transformadora, na medida em que provoca rupturas e pode ser identificada como uma práxis revolucionária, [...].(SOUSA, 2000, p. 126).

Entendemos que a extensão universitária no processo formativo pode vir a ser para a manutenção ou emancipação das relações sociais, tornando-se, a nosso ver, um importante elemento de análise. Essa concepção carrega em si o sentido de transformação social e de atividade acadêmica pela práxis, as quais são congruentes com a concepção e sentido que defendemos para as ações extensionistas, apesar de entendermos que essas ações por si mesmas não transformam a sociedade, mas criam aos sujeitos as condições para que estes transformem suas práticas, seus conhecimentos e, por consequência, suas relações homem-natureza. Essas relações devem visar o coletivo e não somente o individual, de forma crítica e emancipadora, que possa, de maneira mediata, mudar as relações de produção.

E é como práxis revolucionária que entendemos o papel da Extensão hoje. É esta sua responsabilidade. Só desta forma a Universidade poderá ser aceita como instrumento transformador do real, quando estiver atuando sobre as mudanças das circunstâncias mas também sendo transformada por essas mesmas circunstâncias. (SOUSA, 2000, p. 130).

Sousa (2000, p. 127) afirma que "[...] a partir do momento em que uma concepção de Extensão Universitária passa a ser assumida pelos sujeitos de sua prática, definem-se os caminhos que podem ser trilhados.”. Não se pode fazer extensão universitária por fazer. É preciso intencionalidade. Para tal as instituições precisam assumir a concepção e o sentido da extensão universitária enquanto acadêmica, crítica e emancipadora, se afastando da prestação de serviço, mas, para a autora a extensão universitária ainda é vista como uma atividade acadêmica-empresarial, sem movimento para essa mudança, mas que precisa ser desnudada do em seu projeto neoliberal.

Todas essas questões precisam ser consideradas, ainda que Saviani (2009, p. 149) apresenta que a universidade "[...] nunca se preocupou com a formação específica, isto é, com o preparo pedagógico-didático dos professores.” e as atividades de extensão universitárias podem favorecer o preparo didático-pedagógico envolto de conteúdos. A discussão de Saviani (2009) quanto a contradição entre forma e conteúdo, aborda que muitas institucionais tratam da forma e esquecem do conteúdo ou tratam do conteúdo e 
esquecem da forma. De modo em geral, as instituições não tem se preocupado com a formação teórica, com o embasamento teórico, dedicando à dimensão técnica. Essas questões estão postas não somente no ensino, mas também na extensão.

O FORPROEX (2012) apresenta que o sentido das ações extensionistas deve ser de processo acadêmico, que ao longo da continuidade da ação pode vir a favorecer a formação docente pela indissociabilidade com a pesquisa e o ensino, além de que o desafio para a extensão universitária é garantir sua dimensão acadêmica como impacto na formação do estudante, abandonando a prática de ações isoladas como prestação de serviço e a agenda estratégica para a extensão universitária é reconhecer seu potencial formativo. Assim, as diretrizes da extensão universitária do FORPROEX (2012) se configuram por: interação dialógica, interdisciplinaridade e interprofissionalidade, indissociabilidade ensino-pesquisa-extensão, impacto na formação do estudante e, finalmente, impacto e transformação social, e que, precisa ter suas ações avaliadas segundo as dimensões: política de gestão, infraestrutura, relação universidade- sociedade, plano acadêmico e produção acadêmica. Essas questões podem não garantir que as ações de extensão sejam de fato voltadas para a formação do estudante, mas pelo menos as orientam em como ser.

Compreender a concepção e o sentido que os docentes apresentam em relação a extensão no processo formativo, bem como os limites e as perspectivas de construção e desenvolvimento de ações extensionistas no movimento da formação do estudante, se torna imprescindível. Destarte, compreender o movimento do como fazer, porque fazer e para quem fazer anuncia a concepção e o sentido das ações extensionistas. Com esse escopo teórico, defendemos que a concepção de extensão universitária deve ser acadêmica, processual e orgânica e que o sentido da mesma seja de formação do acadêmico crítico e emancipado, transformação da sociedade e produção do conhecimento científico.

\section{EXTENSÃO UNIVERSITÁRIA E FORMAÇÃO DOCENTE: o que dizem os docentes sobre concepções e sentidos}

A análise do grupo de coordenadores dos projetos de extensão, até o dia das entrevistas dos 9 professores, aponta que no tocante a formação 8 eram especialistas e 1 doutor e quanto ao vínculo contratual com a instituição 7 eram temporários e 2 efetivos. Esses dados possibilitam compreender um pouco do movimento dialético e contraditório 
da realização das atividades de cada projeto de extensão, mediante suas possibilidades e limites, para alcançarmos a concepção, o sentido e a construção da extensão universitária no processo formativo.

O Quadro n. 01 apresenta a concepção e o sentido que os coordenadores têm sobre a da extensão universitária.

Quadro n. 01 - Pré-indicadores sobre concepção e sentido da extensão universitária

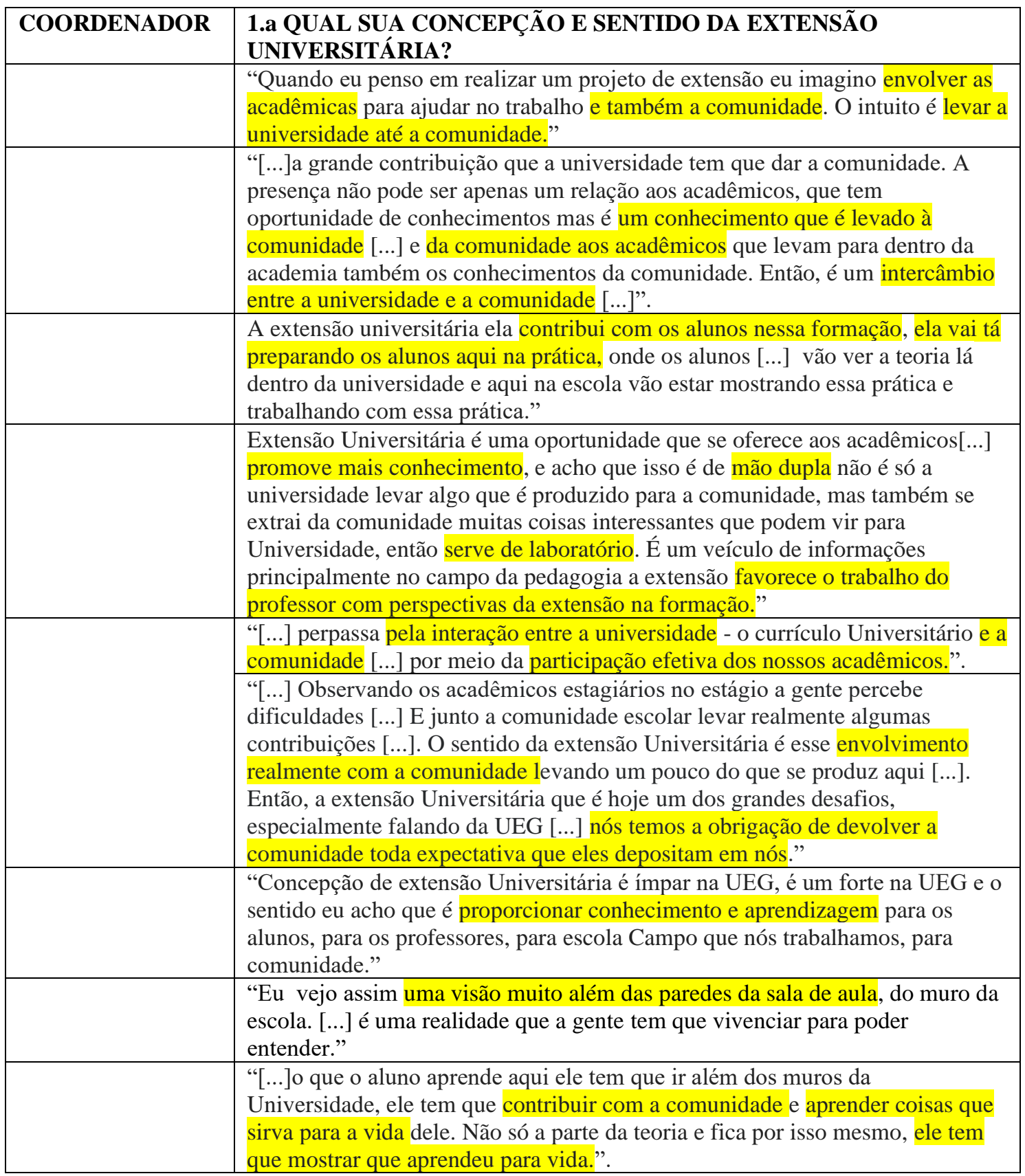

Fonte: As entrevistas (2018) 
Considerando a metodologia analítica dos Núcleos de Significação de Aguiar e Ozella (2013) o Quadro n. 02 apresenta os indicadores de cada respostas dos 9 coordenadores entrevistados sobre a concepção e sentido de extensão universitária.

Quadro n. 02 - Indicadores sobre concepção e sentido da extensão universitária

\begin{tabular}{|c|c|}
\hline COORDENADOR & $\begin{array}{l}\text { 1.a QUAL SUA CONCEPÇÃO E SENTIDO DA EXTENSÃO } \\
\text { UNIVERSITÁRIA? }\end{array}$ \\
\hline Literatura & $\begin{array}{c}* \text { envolver as acadêmicas } * \text { também a comunidade } * \text { levar a universidade até a } \\
\text { comunidade }\end{array}$ \\
\hline Formação & $\begin{array}{l}\text { * um conhecimento que é levado à comunidade *da comunidade aos } \\
\text { acadêmicos } \\
\text { * intercâmbio entre a universidade e a comunidade }\end{array}$ \\
\hline História & $\begin{array}{l}\text { * contribui com os alunos nessa formação * preparando os alunos aqui na } \\
\text { prática }\end{array}$ \\
\hline Jogos & $\begin{array}{l}* \text { promove mais conhecimento } * \text { mão } * \text { serve de laboratório } * \text { favorece o } \\
\text { trabalho do professor com perspectivas da extensão na formação }\end{array}$ \\
\hline \multirow[t]{2}{*}{ Trânsito } & * pela interação entre a comunidade e a universidade * \\
\hline & $\begin{array}{l}\text { * envolvimento realmente com a comunidade * nós temos a obrigação de } \\
\text { devolver a comunidade toda expectativa que eles depositam em nós }\end{array}$ \\
\hline EJA & * proporcionar conhecimento e aprendizagem \\
\hline Reforço & * visão muito além das paredes da sala de aula \\
\hline Ciências & $\begin{array}{l}* \text { contribuir com a comunidade * aprender coisas que sirva para a vida * ele } \\
\text { tem que mostrar que aprendeu para vida }\end{array}$ \\
\hline
\end{tabular}

Fonte: As entrevistas (2018)

Com a organização dos indicadores foi possível organizar os núcleos de significação, representados no Quadro n. 03 que aborda a concepção e sentido de extensão universitária para os coordenadores dos projetos.

Quadro n. 03 - Núcleos de significação sobre concepção e sentido da extensão universitária

\begin{tabular}{|c|c|}
\hline Indicadores & Núcleos de Significação \\
\hline $\begin{array}{l}\text { * envolver as acadêmicas } \\
\text { * também a comunidade } \\
\text { * da comunidade aos acadêmicos } \\
\text { * intercâmbio entre a universidade e a } \\
\text { comunidade } \\
\text { * mão dupla } \\
\text { * pela interação entre a universidade e a } \\
\text { comunidade } \\
\text { * envolvimento realmente com a comunidade }\end{array}$ & $\begin{array}{l}\text { * processo bilateral } \\
\text { * contribuição social }\end{array}$ \\
\hline $\begin{array}{l}\text { * nós temos a obrigação de devolver a } \\
\text { comunidade toda expectativa que eles } \\
\text { depositam em nós } \\
\text { * contribuir com a comunidade } \\
\text { *levar a universidade até a comunidade } \\
\text { * um conhecimento que é levado à } \\
\text { comunidade }\end{array}$ & * formação acadêmica \\
\hline * contribui com os alunos nessa formação & \\
\hline
\end{tabular}




\begin{tabular}{|l|l|}
\hline * preparando os alunos aqui na prática & \\
* promove mais conhecimento & \\
* serve de laboratório & \\
* favorece o trabalho do professor com & * protagonismo acadêmico para a vida \\
perspectivas da extensão na formação & \\
* proporcionar conhecimento e aprendizagem & \\
* visão muito além das paredes da sala de & \\
aula & \\
\hline * participação efetiva dos nossos acadêmicos & \\
* aprender coisas que sirva para a vida & \\
* ele tem que mostrar que aprendeu para vida & \\
\hline
\end{tabular}

Fonte: As entrevistas (2018)

Os núcleos de significação no tocante a concepção e sentido de extensão universitária que os coordenadores dos projetos têm apresentam que compreendem ser um processo bilateral bem como compreendem que o sentido da extensão é a formação acadêmica em que o este é o protagonista com aprendizagem para a vida e reconhecem a contribuição social.

A compreensão da extensão universitária como um processo bilateral ficou evidenciado pelos relatos de que é preciso envolver os acadêmicos e também a comunidade, por meio de um intercâmbio entre a universidade e a comunidade como um processo de mão dupla, de levar e buscar conhecimentos, de aprendizagem recíproca, pela troca de saberes, como proposto pelo FORPROEX (2012).

[...]a grande contribuição que a universidade tem que dar a comunidade. A presença não pode ser apenas um relação aos acadêmicos, que tem oportunidade de conhecimentos mas é um conhecimento que é levado à comunidade [...] e da comunidade aos acadêmicos que levam para dentro da academia também os conhecimentos da comunidade. Então, é um intercâmbio entre a universidade e a comunidade [...] (Coordenador, Projeto Formação)

Extensão Universitária é uma oportunidade que se oferece aos acadêmicos[...] promove mais conhecimento, e acho que isso é de mão dupla não é só a universidade levar algo que é produzido para a comunidade, mas também se extrai da comunidade muitas coisas interessantes que podem vir para Universidade, então serve de laboratório. É um veículo de informações principalmente no campo da pedagogia a extensão favorece o trabalho do professor com perspectivas da extensão na formação. (Coordenador, Projeto Jogos)

Quando eu penso em realizar um projeto de extensão eu imagino envolver as acadêmicas para ajudar no trabalho e também a comunidade. O intuito é levar a universidade até a comunidade. (Coordenador, Projeto Literatura)

Enquanto que o sentido da extensão universitária perpassa pela contribuição social que as atividades extensionistas promovem, sendo que foi constatado pelos relatos de que existe a obrigação de devolver a comunidade toda expectativa que eles depositam na 
universidade e dessa forma contribuir com a mesma, levando os conhecimentos produzidos na universidade para a comunidade, o que pode favorecer a transformação social.

Quando eu penso em realizar um projeto de extensão eu imagino envolver as acadêmicas para ajudar no trabalho e também a comunidade. O intuito é levar a universidade até a comunidade. (Coordenador, Projeto Literatura)

[...]a grande contribuição que a universidade tem que dar a comunidade. A presença não pode ser apenas um relação aos acadêmicos, que tem oportunidade de conhecimentos mas é um conhecimento que é levado à comunidade [...]. (Coordenador, Projeto Formação)

[...] que o aluno aprende aqui ele tem que ir além dos muros da Universidade, ele tem que contribuir com a comunidade e aprender coisas que sirva para a vida dele. Não só a parte da teoria e fica por isso mesmo, ele tem que mostrar que aprendeu para vida. (Coordenador, Projeto Ciência)

[...] O sentido da extensão Universitária é esse envolvimento realmente com a comunidade levando um pouco do que se produz aqui [...]. Então, a extensão Universitária que é hoje um dos grandes desafios, especialmente falando da UEG [...] nós temos a obrigação de devolver a comunidade toda expectativa que eles depositam em nós. (Coordenador, Projeto Trânsito)

Entretanto o sentido da extensão universitária também ficou evidente que os docentes compreendem que se estabelece pela formação acadêmica, em que as atividades extensionistas preparam os acadêmicos na prática pois vai além dos muros da universidade, promovendo mais conhecimentos e aprendizagens por um processo de laboratório, cujo defende Gurgel (1986), corroborando com Reis (1996, p. 44) ao afirmar sobre a importância de um "mergulhar no real concreto com suas contradições." Em alguns momentos podemos dizer que a palavra prática pode ser compreendida como práxis.

A extensão universitária ela contribui com os alunos nessa formação, ela vai tá preparando os alunos aqui na prática, onde os alunos [...] vão ver a teoria lá dentro da universidade e aqui na escola vão estar mostrando essa prática e trabalhando com essa prática. (Coordenador, Projeto de História)

Eu vejo assim uma visão muito além das paredes da sala de aula, do muro da escola. [...] é uma realidade que a gente tem que vivenciar para poder entender. (Coordenador, Projeto Reforço)

Concepção de extensão Universitária é ímpar na UEG, é um forte na UEG e o sentido eu acho que é proporcionar conhecimento e aprendizagem para os alunos, para os professores, para escola Campo que nós trabalhamos, para comunidade. (Coordenador, Projeto EJA) 
Já quanto ao acadêmico ser protagonista e com aprendizagem para a vida enquanto sentido da extensão universitária foi possível concluir porque os docentes tem clareza que a participação dos acadêmicos deve ser efetiva e não somente de observação, o que pode favorecer aprendizagens para a vida e não somente de um conteúdo ou tema específico do projeto, pois para Síveres (2013) o acadêmico precisa ser sujeito e não mero expectador. Dessa forma, as atividades de extensão pode favorecer a transformação do acadêmico.

[...] que o aluno aprende aqui ele tem que ir além dos muros da Universidade, ele tem que contribuir com a comunidade e aprender coisas que sirva para a vida dele. Não só a parte da teoria e fica por isso mesmo, ele tem que mostrar que aprendeu para vida. (Coordenador, Projeto Ciência)

[...] perpassa pela interação entre a universidade - o currículo Universitário e a comunidade [...] por meio da participação efetiva dos nossos acadêmicos. (Coordenador, Projeto Trânsito)

Destarte, concluímos que a concepção de extensão universitária dos docentes é de um processo bilateral de produção de conhecimentos acadêmicos no movimento real e contraditório e, que seu sentido é a formação acadêmica e a contribuição social, fomentando a transformação do real de forma mediata.

\section{EXTENSÃO UNIVERSITÁRIA E FORMAÇÃO DOCENTE: o que dizem os docentes sobre limites e perspectivas}

Para uma análise mais detalhada em relação a extensão universitária e a formação docente, não basta apenas analisar a concepção e o sentido dessa relação na visão dos docentes. É preciso analisar também os limites e as perspectivas que os 9 professores, apontam sobre a questão, visto que o movimento é contraditório e que a construção dessa relação é afetada diretamente pelos limites, mas podendo avançar nas perspectivas.

O Quadro n. 04 apresenta os pré-indicadores dos limites e as perspectivas que os docentes percebem em relação a extensão universitária na formação docente.

Quadro n. 04 - Pré-Indicadores sobre os limites e perspectivas da extensão na formação docente

\begin{tabular}{|l|l|}
\hline COORDENADOR & $\begin{array}{l}\text { 1.b QUAIS OS LIMITES E AS PERSPECTIVAS DA EXTENSÃO UNIVERSITÁRIA } \\
\text { NA FORMAÇÃO DOCENTE? }\end{array}$ \\
\hline Literatura & $\begin{array}{l}\text { "[... eu já tive um projeto que não era da minha formação então encontrei muitas } \\
\text { dificuldades e limites, mas nesse projeto eu não encontro assim muitos limites porque é uma } \\
\text { área que eu estudei bastante, as alunas envolveram bastante }[. . .] ”\end{array}$ \\
\hline
\end{tabular}




\begin{tabular}{|c|c|}
\hline Formação & $\begin{array}{l}\text { "[...] O grande limite pra gente }[\ldots] \text { são acadêmicas que são trabalhadoras [...] o tempo para } \\
\text { extensão fica muito restrito [...] acho que é o grande limite da extensão. Existe } \\
\text { possibilidade, tanto que a gente faz dentro desses limites. É possível fazer com boa vontade } \\
\text { a gente consegue fazer.”. }\end{array}$ \\
\hline História & $\begin{array}{l}\text { "Acho que os limites não tem, eles vão extrapolar todos os limites que eles conseguirem e } \\
\text { essas perspectivas é que realmente esse trabalho com extensão vai contribuir para formação } \\
\text { acadêmica e para vida do aluno.". }\end{array}$ \\
\hline Jogos & $\begin{array}{l}\text { "Como limites o pouco incentivo da extensão nos cursos[...] os alunos não ficam sabendo } \\
\text { dos projetos de extensão, são poucas as oportunidades, poucos professores são } \\
\text { extensionistas. [...] as poucas oportunidades de bolsa também e os alunos nem sempre } \\
\text { vislumbram participar da extensão Universitária porque... acaba que eles não veem muito } \\
\text { significado, [...] o nosso curso precisa de mostrar mais esses projetos que são desenvolvidos } \\
\text { talvez porque na medida que visualiza, valoriza. Sobre as possibilidades da extensão seria } \\
\text { promover um intercâmbio maior e permitir que a formação docente seja mais } \\
\text { enriquecida, [...] e que se consolida esse discurso de indissociabilidade ensino, pesquisa e } \\
\text { extensão, fala-se muito nisso mas nem sempre a gente vê que se efetiva na prática. [...] } \\
\text { Trazer a extensão para colaborar mais com o ensino e vice-versa." }\end{array}$ \\
\hline \multirow[t]{2}{*}{ Trânsito } & $\begin{array}{l}\text { "[...] é de grande valia porque eu preciso me formar para depois eu fazer essa formação com } \\
\text { os acadêmicos participantes do projeto e consequentemente isso gera um aprendizado muito } \\
\text { grande. [...] existem limites para a execução do projeto de extensão, hoje a questão da carga } \\
\text { horária porque quando a gente tem a possibilidade de ter outro colega nos ajudando na } \\
\text { coordenação a gente acaba que divide a carga horária do projeto. A questão também de } \\
\text { recursos financeiros [...] acaba que fica um pouco dispendioso mas nem por isso a gente } \\
\text { deixa de desenvolver o projeto." }\end{array}$ \\
\hline & $\begin{array}{l}\text { “[...] não há como separar está inserido na formação tudo que nós buscamos e fazemos } \\
\text { enquanto extensão é conhecimento científico, trás construção, faz sentido para nossa } \\
\text { formação. Os limites a gente esbarra mais na questão mesmo do apoio [...] que envolvem } \\
\text { financiamento, [...] se falta a parte financiadora o incentivo também acaba sendo menor por } \\
\text { muitos professores talvez não se envolve indiretamente por conta desse fator. A extensão } \\
\text { contribui na formação de professores [...] quando você leva para uma comunidade, } \\
\text { especialmente comunidades mais carentes, uma possibilidade de trabalhar além do que tem } \\
\text { sido feito na sala de aula, você faz grande diferença, você incentiva o professor que está lá, } \\
\text { a voltar os olhos para sua formação e para nós professores universitários [...] a extensão trás } \\
\text { esse contato direto com outro e eu vejo como estágio, uma formação em serviço, uma } \\
\text { formação in loco, com a prática, direto realmente fazendo a diferença.”. }\end{array}$ \\
\hline EJA & $\begin{array}{l}\text { "[...] eu vejo que alguns acadêmicos eles têm uma concepção de extensão só para } \\
\text { graduação, é como se fosse algo que ele tem que cumprir porque ele precisa formar, porque } \\
\text { ele ainda não tem essa concepção do conhecimento maior que pode ser utilizado lá fora. Eu } \\
\text { vejo que alguns fazem por pressão porque tem que fazer que se não fazer não recebe o } \\
\text { certificado de graduação. E isso atrapalha na formação deles. [...] alguns não gostariam de } \\
\text { fazer nenhum e fazem porque tem que fazer o que são recebe a graduação.”. }\end{array}$ \\
\hline Reforço & $\begin{array}{l}\text { "Entre os limites eu percebo a falta de incentivo [...] fica muito a desejar. É falta de } \\
\text { recursos financeiros que a gente percebe isso também, mas isso ai não impede da gente faz } \\
\text { o nosso trabalho, a gente faz o trabalho da maneira que pode, e que dá certo e muitas vezes } \\
\text { com os nossos próprios recursos." }\end{array}$ \\
\hline Ciências & $\begin{array}{l}\text { "Olha os limites em termos de conhecimento.[...] Porque você tem que preparar o aluno da } \\
\text { UEG para mandar para as escolas [...] Mesmo o acadêmico tendo cursado as disciplinas, a } \\
\text { gente pressupõe que o aluno quando vem para Universidade [...] ele tenha domínio desse } \\
\text { conteúdo, mas não, você tem que ensinar tudo de novo e não é só relembrar você tem que } \\
\text { ensinar porque não aprenderam nas escolas e ainda ensinar a metodologia. [...]". }\end{array}$ \\
\hline
\end{tabular}

Fonte: As entrevistas (2018)

O Quadro n. 05 apresenta os indicadores dos limites e as perspectivas que os docentes percebem em relação a extensão universitária na formação docente. 


\begin{tabular}{|c|c|}
\hline COORDENADOR & $\begin{array}{l}\text { 1.b QUAIS OS LIMITES E AS PERSPECTIVAS DA EXTENSÃO UNIVERSITÁRIA } \\
\text { NA FORMAÇÃO DOCENTE? }\end{array}$ \\
\hline Literatura & * não era da minha formação * as alunas envolveram bastante \\
\hline Formação & * acadêmicas que são trabalhadoras *o tempo * possível fazer com boa vontade \\
\hline História & $\begin{array}{c}\text { * vão extrapolar todos os limites *vai contribuir para formação acadêmica e para vida do } \\
\text { aluno }\end{array}$ \\
\hline Jogos & $\begin{array}{c}\text { * o pouco incentivo da extensão * os alunos não ficam sabendo dos projetos *são poucas as } \\
\text { oportunidades * poucas oportunidades de bolsa * eles não veem muito significado* } \\
\text { intercâmbio maior * formação docente seja mais enriquecida* indissociabilidade nem } \\
\text { sempre a gente vê que se efetiva na prática }\end{array}$ \\
\hline \multirow[t]{2}{*}{ Trânsito } & $\begin{array}{l}\text { *eu preciso me formar para depois eu fazer essa formação com os acadêmicos * carga } \\
\text { horária * recursos financeiros } * \text { um pouco dispendioso } * \text { mas nem por isso a gente deixa de } \\
\text { desenvolver o projeto }\end{array}$ \\
\hline & $\begin{array}{l}\text { * inserido na formação * envolvem financiamento* contribui na formação de professores * } \\
\text { comunidades mais carentes*eu vejo como estágio, uma formação em serviço, uma formação } \\
\text { in loco, com a prática direto * realmente fazendo a diferença }\end{array}$ \\
\hline EJA & $\begin{array}{l}\text { *ele tem que cumprir porque ele precisa formar* não tem essa concepção do conhecimento } \\
\text { maior * alguns fazem por pressão * isso atrapalha na formação }\end{array}$ \\
\hline Reforço & $\begin{array}{l}* \text { falta de incentivo * falta de recursos financeiros * não impede * muitas vezes com os } \\
\text { nossos próprios recursos }\end{array}$ \\
\hline Ciências & $\begin{array}{l}* \text { falta de conhecimento* você tem que preparar o aluno da UEG para mandar para as } \\
\text { escolas * ensinar tudo de novo e ainda ensinar a metodologia }\end{array}$ \\
\hline
\end{tabular}
Fonte: As entrevistas (2018)

Com a organização dos indicadores foi possível organizar os núcleos de significação, que estão representados no Quadro n. 06 que aborda os limites e as perspectivas da extensão universitária na formação acadêmica.

Quadro n. 06 - Núcleos de significação sobre os limites e perspectivas da extensão na formação docente

\begin{tabular}{|c|c|}
\hline Indicadores & Núcleos de Significação \\
\hline $\begin{array}{l}\text { * carga horária } \\
\text { * recursos financeiros } \\
\text { * envolvem financiamento } \\
\text { * falta de recursos financeiros } \\
\text { * poucas oportunidades de bolsa } \\
\text { * falta de incentivo } \\
\text { * o pouco incentivo da extensão } \\
\text { * os alunos não ficam sabendo dos projetos } \\
\text { *são poucas as oportunidades } \\
\text { * eles não veem muito significado }\end{array}$ & * limites institucionais \\
\hline $\begin{array}{l}\text { * não era da minha formação } \\
\text { * acadêmicas que são trabalhadoras } \\
\text { *o tempo } \\
\text { *ele tem que cumprir porque ele precisa formar } \\
\text { * não tem essa concepção do conhecimento } \\
\text { maior } \\
\text { * alguns fazem por pressão } \\
\text { * isso atrapalha na formação } \\
\text { * falta de conhecimento } \\
\text { * você tem que preparar o aluno da UEG para } \\
\text { mandar para as escolas }\end{array}$ & * limites pedagógicos \\
\hline
\end{tabular}




\begin{tabular}{|c|c|}
\hline $\begin{array}{l}\text { * ensinar tudo de novo e ainda ensinar a } \\
\text { metodologia }\end{array}$ & \\
\hline $\begin{array}{l}\text { * possível fazer com boa vontade } \\
\text { * vão extrapolar todos os limites } \\
\text { * um pouco dispendioso } \\
\text { * mas nem por isso a gente deixa de } \\
\text { desenvolver o projeto } \\
\text { * não impede } \\
\text { * muitas vezes com os nossos próprios recursos }\end{array}$ & * precarização do trabalho docente \\
\hline $\begin{array}{l}\text { *vai contribuir para formação acadêmica e para } \\
\text { vida do aluno } \\
\text { * formação docente seja mais enriquecida } \\
\text { * indissociabilidade nem sempre a gente vê que } \\
\text { se efetiva na prática } \\
\text { * as alunas envolveram bastante } \\
\text { *eu preciso me formar para depois eu fazer essa } \\
\text { formação com os acadêmicos } \\
\text { * inserido na formação } \\
\text { * contribui na formação de professores } \\
\text { *eu vejo como estágio, uma formação em } \\
\text { serviço, uma formação in loco, com a prática } \\
\text { direto } \\
\text { * você tem que preparar o aluno da UEG para } \\
\text { mandar para as escolas } \\
\text { * ensinar tudo de novo e ainda ensinar a } \\
\text { metodologia }\end{array}$ & $\begin{array}{l}\text { * contribuição na formação } \\
\text { * contribuição social }\end{array}$ \\
\hline $\begin{array}{l}\text { * comunidades mais carentes } \\
\text { * intercâmbio maior } \\
\text { * realmente fazendo a diferença }\end{array}$ & \\
\hline
\end{tabular}

Para compreender as concepções, os sentidos e principalmente, as construções da extensão universitária no processo formativos dos acadêmicos, é importante considerar nas análises os limites e as perspectivas. Nesse interim os núcleos de significação no tocante aos limites e perspectivas da extensão universitária na formação docente na percepção dos docentes se estruturam por reconhecem os limites institucionais de ordem financeiros e pedagógico, percebem os limites pedagógicos, de tempo e conhecimento, naturalizam a precarização do trabalho docente, porém como perspectivas compreendem a contribuição na formação e percebem a contribuição social.

Quanto aos limites institucionais ficou evidente que estes são de ordem financeiros e pedagógico, no tocante a baixa carga horária destinada aos coordenadores, a falta de recursos financeiros para compra de materiais, a pouca oferta de bolsas, bem como a falta de incentivo até mesmo quanto a divulgação dos projetos e oferta de variados projetos. Em relação ao financiamento das ações e a alocação da carga horária, Reis (1996, p. 46) defende que é preciso uma decisão político-orçamentária e que a “[...] carga 
horária contemple sem a concepção acadêmica-administrativa a articulação ensino, pesquisa, extensão e administração [...].”. Sobre isso Sousa (2000, p. 101) argumenta que concepção, institucionalização e financiamento "são questões fundamentais sobre as atividades extensionistas." e que precisam ser discutidas e sanadas. Limites que podem dificultar a construção de projetos de extensão que promovam uma formação acadêmica consistente, mesmo que os docentes tenham a concepção acadêmica processual, orgânica e de aprendizagem e o sentido de formação e transformação social.

\begin{abstract}
Como limites o pouco incentivo da extensão nos cursos[...] os alunos não ficam sabendo dos projetos de extensão, são poucas as oportunidades, poucos professores são extensionistas. [...] as poucas oportunidades de bolsa também e os alunos nem sempre vislumbram participar da extensão Universitária porque... acaba que eles não veem muito significado, [...] o nosso curso precisa de mostrar mais esses projetos que são desenvolvidos talvez porque na medida que visualiza, valoriza. Sobre as possibilidades da extensão seria promover um intercâmbio maior e permitir que a formação docente seja mais enriquecida, [...] e que se consolida esse discurso de indissociabilidade ensino, pesquisa e extensão, fala-se muito nisso mas nem sempre a gente vê que se efetiva na prática. [...] Trazer a extensão para colaborar mais com o ensino e vice-versa. (Coordenador, Projeto Jogos)

[...] é de grande valia porque eu preciso me formar para depois eu fazer essa formação com os acadêmicos participantes do projeto e consequentemente isso gera um aprendizado muito grande. [...] existem limites para a execução do projeto de extensão, hoje a questão da carga horária porque quando a gente tem a possibilidade de ter outro colega nos ajudando na coordenação a gente acaba que divide a carga horária do projeto. A questão também de recursos financeiros [...] acaba que fica um pouco dispendioso mas nem por isso a gente deixa de desenvolver o projeto. (Coordenador, Projeto Trânsito)
\end{abstract}

Além dos limites institucionais, percebem os limites pedagógicos, visto que ficou explícito pelos relatos que se refere a docente, mas principalmente, aos acadêmicos no tocante a falta de tempo e de conhecimentos. Quanto ao docente um limite apresentado foi sobre sua falta de formação com a temática do projeto que havia assumido. Quanto aos acadêmicos a questão do tempo por serem trabalhadores, por não terem a concepção e o sentido de extensão universitária esclarecidos no seu processo formativo, fazendo-a por obrigação e também por apresentarem fragilidades de conteúdos que deveriam ter apreendidos no Ensino Fundamental e Médio. Saviani (2009) discute que a formação de professores no Brasil apresenta uma certa dicotomia entre forma e conteúdo e que muitas vezes “[...] a questão educativa é reduzida dominantemente à sua dimensão técnica, afastando-se [...] de embasamento científico.”. Em relação ao público da UEG ser de trabalhadores corrobora com o sentido de sua criação, pois supostamente primou por atender também a massa trabalhadora do interior do Estado de Goiás, já que segundo o 
PDI (2010, p. 19) foi criada "[...] visando atender as demandas da sociedade goiana [...]". Contudo, precisa criar as condições para que o acadêmico possa permanecer na instituição e ter viabilidade de desenvolver suas atividades ao longo do processo formativo, tanto do ensino quanto da pesquisa e extensão.

[...] O grande limite pra gente [...] são acadêmicas que são trabalhadoras [...] o tempo para extensão fica muito restrito [...] acho que é o grande limite da extensão. Existe possibilidade, tanto que a gente faz dentro desses limites. É possível fazer com boa vontade a gente consegue fazer. (Coordenador, Projeto Formação)

Olha os limites em termos de conhecimento.[...] Porque você tem que preparar o aluno da UEG para mandar para as escolas [...] Mesmo o acadêmico tendo cursado as disciplinas, a gente pressupõe que o aluno quando vem para Universidade [...] ele tenha domínio desse conteúdo, mas não, você tem que ensinar tudo de novo e não é só relembrar você tem que ensinar porque não aprenderam nas escolas e ainda ensinar a metodologia. [...]. (Coordenador, Projeto Ciência)

[...] eu já tive um projeto que não era da minha formação então encontrei muitas dificuldades e limites, mas nesse projeto eu não encontro assim muitos limites porque é uma área que eu estudei bastante, as alunas envolveram bastante [...] (Coordenador, Projeto Literatura)

Outra constatação foi em relação a naturalizarem a precarização do trabalho docente, evidenciado pelos relatos de que extensão se faz pela boa vontade, que mesmo tendo as dificuldades conseguem realizar e inclusive extrapolar esses limites, que mesmo sendo dispendioso financeiramente, desenvolvem o projeto com os próprios recursos, assumindo a responsabilidade que é institucional, no caso da UEG.

Acho que os limites não tem, eles vão extrapolar todos os limites que eles conseguirem e essas perspectivas é que realmente esse trabalho com extensão vai contribuir para formação acadêmica e para vida do aluno. (Coordenador, Proejto História)

[...] O grande limite pra gente [...] são acadêmicas que são trabalhadoras [...] o tempo para extensão fica muito restrito [...] acho que é o grande limite da extensão. Existe possibilidade, tanto que a gente faz dentro desses limites. É possível fazer, com boa vontade a gente consegue fazer. (Coordenador, Projeto Formação)

[...] existem limites para a execução do projeto de extensão, hoje a questão da carga horária porque quando a gente tem a possibilidade de ter outro colega nos ajudando na coordenação a gente acaba que divide a carga horária do projeto. A questão também de recursos financeiros [...] acaba que fica um pouco dispendioso mas nem por isso a gente deixa de desenvolver o projeto. (Coordenador, Projeto Trânsito)

Entre os limites eu percebo a falta de incentivo [...] fica muito a desejar. É falta de recursos financeiros que a gente percebe isso também, mas isso ai não impede da gente faz o nosso trabalho, a gente faz o trabalho da maneira que 
pode, e que dá certo e muitas vezes com os nossos próprios recursos. (Coordenador, Projeto Reforço)

Uma questão que no movimento dialético dos limites e perspectivas precisa ser considerado é que os docentes compreendem a contribuição das atividades de extensão na formação docente. Essa questão ficou evidente nos relatos ao afirmarem que vai além de uma formação acadêmica, pois favorece a vida do aluno como um todo, não somente o profissional mas o humano. Isso ocorre quando há o envolvimento de fato do acadêmico e um processo de indissociabilidade que não fique apenas no campo da imaginação. A extensão precisa ser reconhecida como um estágio ou uma formação em serviço, que promove a formação tanto do professor universitário quanto do acadêmico, seja em termos de conteúdos ou de metodologias. O protagonismo acadêmico é um dos elementos que o FORPROEX (2012) defende e que para Gurgel (1996) isso é possível quando o acadêmico realiza as atividades de extensão como um laboratório vivo, em que está vivendo sua profissão ainda em formação.

\footnotetext{
Acho que os limites não tem, eles vão extrapolar todos os limites que eles conseguirem e essas perspectivas é que realmente esse trabalho com extensão vai contribuir para formação acadêmica e para vida do aluno. (Coordenador, Projeto História)

[...] eu vejo que alguns acadêmicos eles têm uma concepção de extensão só para graduação, é como se fosse algo que ele tem que cumprir porque ele precisa formar, porque ele ainda não tem essa concepção do conhecimento maior que pode ser utilizado lá fora. Eu vejo que alguns fazem por pressão porque tem que fazer que se não fazer não recebe o certificado de graduação. E isso atrapalha na formação deles. [...] alguns não gostariam de fazer nenhum e fazem porque tem que fazer o que são recebe a graduação. (Coordenador, Projeto EJA)
}

Os docentes relataram que percebem a contribuição social das atividades de extensão porque abordam a vinculação dos projetos com comunidades mais carentes, fomentando um intercâmbio maior entre universidade e sociedade, possibilitando fazer a diferença, tanto para o acadêmico quanto para a comunidade. Contudo, as atividades extensionistas não podem se caracterizar pelo mero assistencialismo, como apresenta Reis (1996) visando sanar um problema imediato, o qual é de responsabilidade do Estado, mas para promover a transformação social, tanto do acadêmico quanto do docente e comunidade. As atividades de extensão devem primar pelo princípio da transformação do acadêmico e da sociedade, como propõe o FORPROEX (2012) e para isso é importante 
que a concepção das atividades seja acadêmica e que suas características sejam processuais e orgânicas.

[...] não há como separar está inserido na formação tudo que nós buscamos e fazemos enquanto extensão é conhecimento científico, trás construção, faz sentido para nossa formação. Os limites a gente esbarra mais na questão mesmo do apoio [...] que envolvem financiamento, [...] se falta a parte financiadora o incentivo também acaba sendo menor por muitos professores talvez não se envolve indiretamente por conta desse fator. A extensão contribui na formação de professores [...] quando você leva para uma comunidade, especialmente comunidades mais carentes, uma possibilidade de trabalhar além do que tem sido feito na sala de aula, você faz grande diferença, você incentiva o professor que está lá, a voltar os olhos para sua formação e para nós professores universitários [...] a extensão trás esse contato direto com outro e eu vejo como estágio, uma formação em serviço, uma formação in loco, com a prática, direto realmente fazendo a diferença. (Coordenador, Projeto Trânsito)

Os limites que os docentes apresentam para as atividades de extensão são institucionais (financiamento e incentivo), pedagógicos (tempo e conhecimento) e de naturalização da precarização do trabalho docente, contudo como perspectivas da extensão é evidente a contribuição na formação acadêmica e social.

\section{CONSIDERAÇÕES}

Ao tecer diálogo sobre concepções, sentidos e construções da extensão universitária na formação docente, tendo como foco os docentes que coordenaram projetos de extensão em 2018, na Universidade Estadual de Goiás, vinculados ao curso de Pedagogia, apresentamos que a concepção de extensão universitária perpassa um processo bilateral de produção de conhecimentos acadêmicos no movimento real e contraditório e, que seu sentido é a formação acadêmica e a contribuição social, fomentando a transformação de forma mediata pelo protagonismo acadêmico, considerando que nas atividades de extensão existem limites de cunho institucional e pedagógico, bem como de precarização do trabalho docente, mas é evidente a perspectiva de contribuição na formação acadêmica e social.

\section{REFERÊNCIAS}

AGUIAR, Wanda Maria Junqueira e OZELLA, Sérgio. Apreensão dos sentidos: aprimorando a proposta dos núcleos de significação. In: Revista Brasileira de Estudos Pedagógicos. Brasília, v. 94, n. 236, p. 299-322, jan./abr. 2013.

FORPROEX. Plano Nacional de Extensão Universitária. 2012. In: 
http://www.utfpr.edu.br/estrutura-universitaria/pro-reitorias/prorec/diretoria-deextensao/documentos-da-extensao-de-ambito-nacional/politica-nacional-de-extensaouniversitaria-forproex-2012/view

GURGEL, Roberto Mauro. Extensão Universitária: Comunicação ou Domesticação. São Paulo Cortez, Editora EUFC, Autores Associados, 1986.

PDI. Plano de Desenvolvimento Institucional. UEG - 2010 - 2019. In:

http://www.cdn.ueg.br/arquivos/jussara/conteudoN/598/pdi_aprovado_csu.pdf

PNE. Plano Nacional de Educação. 2014. In:

http://pne.mec.gov.br/images/pdf/pne_conhecendo_20_metas.pdf

REIS, Renato Hilário dos. Histórico, Tipologias e Proposições sobre a Extensão Universitária no Brasil. Linhas Críticas. v. 2, n. 2, 1996.

In: http://periodicos.unb.br/index.php/linhascriticas/article/download/6094/5042.

SAVIANI, Dermeval. Formação de professores: aspectos históricos e teóricos do problema no contexto brasileiro. Revista Brasileira de Educação.Vol. 14. N.40 Jan/Abril. 2009. In: http://www.scielo.br/pdf/rbedu/v14n40/v14n40a12.pdf

SÍVERES, Luiz. O Princípio Da Aprendizagem Na Extensão Universitária. In: SÍVERES, Luiz (Org.) A extensão universitária como princípio de aprendizagem. Brasília: Liber, 2013. In: http://unesdoc.unesco.org/images/0023/002320/232083por.pdf

SOUSA, Ana Luiza Lima. A história da extensão universitária. Campinas: Alínea, 2000.

Recebido em: 01/12/2021

Aprovado em: 20/12/2021

Publicado em:23/12/2021 